\title{
The Impact of Macao's Gaming Industry on Family Life
}

An exploratory study

Gertina J. van Schalkwyk, Emilie Tran et Kay Chang

\section{OpenEdition}

\section{Journals}

Édition électronique

URL : http://journals.openedition.org/chinaperspectives/603

DOI : $10.4000 /$ chinaperspectives.603

ISSN : 1996-4617

\section{Éditeur}

Centre d'étude français sur la Chine contemporaine

Édition imprimée

Date de publication : 1 avril 2006

ISSN : 2070-3449

\section{Référence électronique}

Gertina J. van Schalkwyk, Emilie Tran et Kay Chang, « The Impact of Macao's Gaming Industry on

Family Life », China Perspectives [En ligne], 64 | march - april 2006, mis en ligne le 01 avril 2009 consulté le 28 octobre 2019. URL : http://journals.openedition.org/chinaperspectives/603 ; DOI

$10.4000 /$ chinaperspectives. 603

Ce document a été généré automatiquement le 28 octobre 2019

(c) All rights reserved 


\section{The Impact of Macao's Gaming Industry on Family Life}

An exploratory study

Gertina J. van Schalkwyk, Emilie Tran et Kay Chang

1 This project is a comprehensive situation analysis and needs assessment of the psychological well-being of the people of the Macao Special Administrative Region (SAR). Overall the aim is to gain an in-depth understanding of the context and needs of the local community in order to appropriately provide psychological services and to develop models for effective intervention strategies for the Macao community ${ }^{2}$. We report here on the first phase of the project and on some of the many enabling and disabling processes having an impact on the well-being of the local population. The purpose is to describe the present situation with regard to family life in Macao focusing in particular on the impact of the gaming industry on family and the respective subsystems (parents and children). As Macao gains its political and economic importance alongside its booming gaming industry, interest in the studying Macao's infrastructure in social and psychological support systems have become increasingly relevant. The gaming industry, the major of source of employment and revenue in the territory, involves hidden factors compared to other industries in the region and inevitably captures the interest of researchers in psychological and sociological topics.

Research into and literature on family life and psychological aspects of people in Macao is extremely limited. The current knowledge base mainly relies on studies conducted in Hong Kong, and about Chinese expatriates living outside Macao. The majority of researchers who study the psychological aspects of Chinese culture and ethnicity pay little or no attention to the uniqueness of the psycho-social situation and related needs in Macao. In August 2005, an independent group of researchers with government funding conducted a large-scale study on the Quality of Life in Macao covering several dimensions related to how the local population perceive and experience the socioeconomic structures of their daily lives ${ }^{3}$. This study, however, did not consider psychological aspects of people's functioning and well-being. The lack of psychological 
baseline knowledge and the mental health service delivery system, only in its infancy, are thus an important backdrop against which the larger study was conducted.

Traditionally Macao has depended, for the delivery of social services, on an informal network of religious organisations, neighbourhood associations, and various social clans. At present mental health care services are mostly provided by social workers and access to psychological services is limited to visiting professionals from Hong Kong and a few partly trained psychological assistants (counsellors and paraprofessionals). Recent figures show the Macao government supports approximately 89 social workers for the population of about 482,000 people ${ }^{4}$. Figures for social workers in nongovernment organisations and psychologists are not available. This is a matter of particular concern and indicates that Macao is, to an extent, wanting in terms of mental health care services. It also seems that communication and collaboration among most of the service providers are neither well developed nor organised. Adding to the challenge is the lack of providers of psychological services, and a common established practice of loading mental health work tasks onto clergy staff, social workers and health care workers at best.

Family systems

4 The paper describes the present realities of and challenges to family life in Macao. Families often function according to a particular structure, and role appropriation for the different members of the family system develops. The Family Systems approach views the family as a social group of individuals "tied together through their common biological, legal, cultural and emotional history and their implied future" ${ }^{5}$. As a complex emotional unit the family is primarily a living, ongoing entity that is organised as a whole system with its members in continuous interaction and forming relationship patterns that extend over time and space. In the family, interconnecting family members affect each other's thoughts, feelings and actions based upon a "circular causality that transpires between people within a family" ${ }^{\text {, }}$ as well as between the family and the environment. Hence relationships emerge within the family and between the family and social environment that influence individual development and functioning. As a psycho-social entity the family has a distinct influence on each member's development and psychological well-being. The family can in fact be an obstacle to psychological well-being, particularly when the family system faces change to its core values or when a change in the functioning of one person predictably elicits change in the functioning of others.

5 In Macao at least four family groups were identified representing different and unique cultural heritages. Macanese families reflected a mixed-race heritage with Portuguese and Chinese the dominant cultures, and customs that were particular to Macao. Chinese families manifested in two distinct groups with families who migrated to Macao and have been living there for at least three generations in one group, and newer Chinese individuals and families who have migrated to the enclave since the handover to the PRC in 1999 and are considered as first generation authorised residents of Macao in the second group. The majority of families in the latter group came from Guangdong, with 4,848 (70\%) legal immigrants from that province in 2004 alone. Both these groups still adhered to traditional Chinese customs and cultural heritage, with the former showing more acculturation, either with or without strong ties to their families of origin on the mainland. In the latter group the general trend was also for more women to leave their family of origin and come to Macao either with or without 
her children to find employment. An average $61.33 \%$ of legal immigrants from the mainland in 2004 were women ${ }^{7}$. The fourth group of families were mixed: some families were of Portuguese background maintaining strong ties with their country and culture of origin, some expatriate families from around the world, and a fair community of families originating from other Asian countries in the region (e.g., Philippines, Nepal, etc.).

6 Family systems in the multi-cultural context of Macao to a large extent still reflected conservative and traditional values and customs. Although the nuclear family system was evident, we encountered a mixed cultural heritage that influenced values and beliefs about what was considered "normal" family life. The data collected for this project focused mostly on the first three groups of families with Macanese and Chinese heritage, who constituted the largest proportion of the Macao population, with approximately $9.5 \%$ of the population 19 years of age and younger. Although the Macanese families reflected a unique mix in their cultural heritage, all the family systems reflected strong macro-level beliefs about the values of family life, harmonious living and filial piety.

7 Although psychological well-being is not traditionally a concept used in Chinese family systems, folklore and ancient Chinese writings refer to the concept of happiness associated with fu or fuqi (WW), which involves "anything positive and good in life" and related to longevity, prosperity, health, peace, virtue and a comfortable death ${ }^{8}$. This conceptualisation of happiness relates to what is implied by psychological wellbeing as a complex set of behaviours, thoughts, feelings and relationships that underlie the overall physical and socio-emotional wellness of people in a community. Research into the concept of the purpose and meaning of life involves the well-being of individuals and groups in different contexts such as the workplace, explorations regarding the cultural values of happiness, and more recently, psychofortology ${ }^{9}$. Whereas a lack of meaning in life could be associated with psychopathology ${ }^{10}$, some authors ${ }^{11}$ indicate that purpose in and meaning of life constitutes critical components of mental health with an emphasis on a sense of directedness and intentionality. Sources of personal meaning influence coping strategies for stress, while strong religious beliefs, group membership, values, clear goals and dedication to a cause further indicates the extent to which the demands of life are seen as worthy of investment and engagement.

8 It can thus be assumed that psychological well-being for the families of Macao will emerge in this historical time, multi-cultural context and with the boom in the gaming industry when positive emotions are fostered and encouraged while there is a lower level of negative emotions in viewing one's overall satisfaction with life. In order to enhance the psychological well-being of a community, it is necessary to focus on preventive interventions that would decrease risk processes that can contribute to the development of psychological problems and pathologies ${ }^{12}$. Risk processes are those features that reduce the biological, psychological and social capacities of individuals and environments in order to maintain a healthy and well-balanced society. Psychological services would focus on the promotion of coping abilities and the development of adaptive and protective processes both for individuals and environments so as to increase or enhance the capacities for sustained psychological well-being. Frameworks for mental health care services should be developed aimed at 
providing interventions that would answer to the needs of the local population and that are accessible to all members of the community, children, adolescents and adults ${ }^{13}$. The gaming industry in Macao

9 Today few people know anything about Macao other than it is a gambling haven on the south China coast. In fact, this has been so only for the past 150 years and it took time to convert the Chinese passion for gambling into the big business that the gaming industry has become. Up to the mid-nineteenth century, Macao served as a trading post in the lucrative sea trade Portugal had engaged in with Japan, the Philippines, China, Malaysia, India and Europe. It had never been viewed as a real colony by Portugal and in a sense it has only ever been a territory administered in order to reap maximum profits. Although Macao's fortunes experienced ups and downs-depending on how open or closed the Chinese and the Japanese empires were to foreign trade at any particular time-the tiny Portuguese enclave enjoyed a considerable degree of prosperity.

10 It would be wrong though to assume that Macao was nothing more than a commercial entrepôt. Macao has also been a "city of commerce and culture"14. Indeed, it was "in Macao, if anywhere, [that] East and West did meet", as once justly put by Charles Boxer, a renowned historian of the Portuguese in $\mathrm{Asia}^{15}$. The encounter and exchange that occurred in Macao have given the territory its blend of cultural and historical heritage ${ }^{16}$, which uniqueness has been asserted by UNESCO ${ }^{17}$.

11 The Treaty of Nanjing, signed in 1842, not only ended the first Opium War, but also sealed the fate of Macao by establishing Hong Kong ${ }^{18}$ and opening five port cities (Canton, Fuzhou, Xiamen, Ningbo and Shanghai) to foreign residence and trade. Since then, the newborn British colony dominated the maritime trade and provided a base for businesses that Macao had never dreamt of or managed to develop. Having lost its traditional commercial relevance and confronted with the economic and social decline that went along with promising inhabitants emigrating to Hong Kong and elsewhere in search of better opportunities, the administrators of Macao saw their livelihoods deeply threatened and they had to find some other sources of internal revenue. In order to survive, Macao needed to specialise in activities neither Hong Kong nor any nearby port city like Canton could offer, and in 1851 Macao started, amongst other endeavours, the coolie trade ${ }^{19}$. After this trade was prohibited in Hong Kong, Macao became all the more involved and it was mostly subsidised by British, American and Chinese capital, until the Portuguese Crown, under public pressure, prohibited it in 1873.

12 Another strategy thus had to be adopted by the administration and monopolies were granted not only to profitable and innocent commercial activities such as fishing oysters and sales of foodstuffs like salt, fish, pork and beef, but also to more harmful and lucrative trades, such as the one on boiled opium and gambling ${ }^{20}$. The idea of licensed gambling under the governorship of Captain Guimarães (1851-1863) proved a success from the start, and “in 1910, the Governor, reporting to Macao's Deputy in the Portuguese Parliament, stated that 70 percent of all income of the Administration came from the monopolies of gambling and opium and only 30 percent from other sources of revenue" 21 .

13 There have always been some forms of gambling in China, although it was prohibited ${ }^{22}$. Today mahjong is regularly played by local residents at family gatherings and with friends. However, in the context of the prohibition under the imperial regime and later 
added to by the surge of anti-gambling sentiments of the Chinese authorities in the late nineteenth century, the very monopolies granted to gambling legalised gambling in Macao and launched the Portuguese territory as a gambling enclave. This was emphasised further when Hong Kong banned gambling in 1871. Gaming contracts were granted to only a handful of figureheads linked to each other in a complex network of associations, fierce competition and backstabbing.

In 1934 the gambling policy reached a turning point when the local administration for the first time granted a monopoly of all casino-style gambling to the syndicate Tai Xing Company, led by Gao Kening and Fu Laorong, thus formally institutionalising gambling as an industry with carefully designed policies that excluded competition from other potential bidders. Until the 1960 s they managed to secure the monopoly for themselves, and during the Tai Xing Co. era, gambling blossomed in Macao while the ban imposed on gambling in the rest of China had been very strictly enforced by the Chinese Communist Party, which came into power in 1949. Another turning point came in 1962 when the Macao governor, despite the suggestion of the highest authorities in Lisbon, granted the casino franchise to the Sociedade de Turismo e Diversões de Macau (STDM) led by Stanley Ho and Yip Hon. The latter retired from the partnership in 1975, thus allowing Stanley Ho to become the only casino magnate in the territory until the end of the franchise on December 31st 2001. The STDM introduced Western games such as roulette and baccarat to the casinos. Transportation between Hong Kong and Macao was modernised by introducing highly efficient and fast hovercraft jetfoils, which had the direct result of enabling Stanley Ho to consolidate the casino industry in the Portuguese enclave.

In August 2001 the Legislative Assembly of Macao, preparing for the ending of the STDM's 40-year-old monopoly over the territory's gaming industry, passed Law 16/2001 according to which it officially established the "Legal Framework for the Operations of Casino Games of Fortune" and tourism, gaming, conventions and exhibitions, and the service industry became the economic driving force for Macao. The SAR government opened the sector to two new players from Las Vegas: the Las Vegas Sands Corp. and the Wynn Resorts. Altogether with SJM (Sociedade de Jogos de Macau), an affiliate of the former monopoly-holder STDM, the three licensed operators, joined by a few big players, such as MGM, Kerry Packer and Galaxy through joint-ventures, have announced frenzied investments and gigantic casino and hotel developments and projects that are under construction on Macao peninsula and on Cotai, a strip of reclaimed land between the islands of Taipa and Coloane. The area will feature not only casinos and hotels (10,000 rooms in total) but also conference facilities on a grand scale and is expected to employ 150,000 staff. The number of casinos increased from 11 in 2002 to 17 in the third quarter of 2005 and Macao has already become the second largest gaming city in the world, behind Las Vegas in the United States. Thus, as we can see, the gaming monopoly, designed to keep the colonial administration afloat in the mid-nineteenth century, has by far exceeded all expectations. Indeed, in 2003, the Macao Gaming Inspection and Coordination Bureau (GICB, 2003) reported that gaming tax contributed $74 \%$ to the Macao fiscal revenue. In 2004, the total public revenue amounted to 19.6 billion patacas of which 15.2 billion patacas came from the gambling $\operatorname{tax}^{23}$, that is to say $77.8 \%$ of the government fiscal revenue: already a three percentage point increase compared with 2003. 
In this context it is apparent that the gaming industry plays a major role in the lives and well-being of the local population. The economic growth and wealth that the industry has brought to the community, has created numerous employment opportunities and the Statistic and Census Services (DSEC) report that unemployment has decreased from $6.4 \%$ in 2002 to $4.1 \%$ in the third quarter of 2005 with almost $58 \%$ of the population working in the industry. Many young people are lured into working in the industry for salaries that sometimes exceed that of peer graduates in the government and private sectors. Furthermore, the industry not only supports casinos, but also a variety of subsidiary business endeavours. In this regard, young girls are imported to work in the sex trade, while large tourist groups visit the territory on a regular basis mostly to participate in gambling but also to enjoy the historical sites and heritage of Macao. It is estimated that approximately 1 million people visit the territory each month, with PRC national holidays allowing this figure to rise to almost 1.5 million. For last October indeed, with the National Day week-long holiday, the Statistics and Census Service indicated that the total number of visitor arrivals reached $1,663,623$, up $10.2 \%$ year-on-year. Visitors from Mainland China, Hong Kong and Taiwan, increased $9.8 \%, 10.9 \%$ and $2.9 \%$ respectively. In the first ten months of 2005 , visitor arrivals totalled $15,438,078$, up $12.7 \%$ for the same period of last year. The majority of visitors come from mainland China (57.9\% of the total), Hong Kong (28.2\%) and Taiwan (7.8\%), and among the mainland visitors, 491,989 (51.1\%) travelled to Macao under the Individual Visit Scheme ${ }^{24}$. But the "Cotai Strip project...-with thousands of rooms, marinas, large entertainment venues, shopping, dining and huge convention and exhibition facilities-is intended to draw people from farther away... visitors from Japan, Singapore, Thailand, from other places in the Asian region, and from the rest of the world" ${ }^{25}$. Given that the territory comprises only approximately 27 square kilometres, this influx of tourists to the casinos and other facilities create a very definite over-crowdedness not only on the streets of Macao, but in every corner of this small enclave.

Exploration

The research in this first explorative stage of the project utilised the key informant approach $^{26}$. The intention was to gain an in-depth understanding of the present situation is Macao in which the gaming industry poses both direct and indirect benefits and challenges to the well-being of local residents. The key informant approach allowed us to conduct semi-structured focus-group and individual interviews ${ }^{27}$ with individuals considered knowledgeable about the community, the residents and their needs (e.g., professionals, community leaders, church leaders, etc.). Because these informants worked directly with the community and regularly interacted with the families in Macao, they were considered as having a particular insight into the situation in the community. The interviews were recorded on audio tape with the consent of the interviewees obtained prior to the interview session. The audio recordings were transcribed and translated to provide textual data for analysis ${ }^{28}$. Family profiles in the form of three-generation genograms were used to provide information regarding the family structure and family history, and the impact of this history on present and probable future patterns ${ }^{29}$.

1. 
Enabling and Disabling Processes of the Gaming Industry
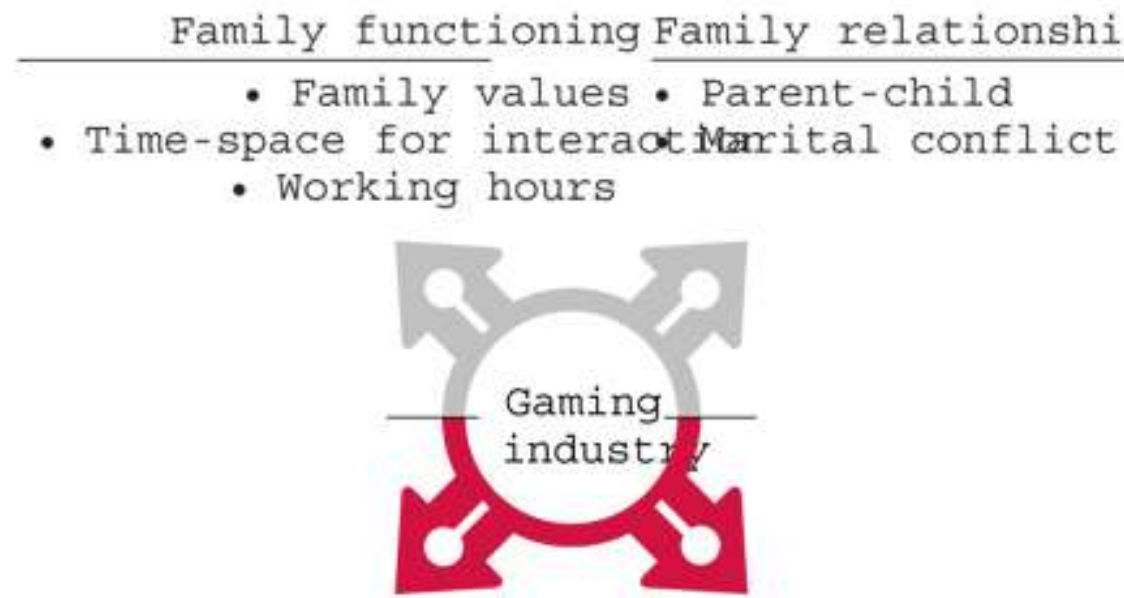

Psycho-social issueschild care

- Employment vs educationUnattended child

- Poverty - Juvenile delinqu

- Dimensions of well-being

18 Two assumptions need to be clarified before continuing with the discussion. In the analysis we focused on the gaming industry in terms of the institutionalisation and legitimisation of gambling as an economic growth entity. We did not at all look into attitudes, habits and behaviour patterns of individuals or families directly involved in gambling itself. Much has been written on gambling behaviour and more will most likely follow. We rather focused the analysis on particular enabling and disabling processes pertaining to psycho-social relationship and behavioural issues related to the perceived impact of the gaming industry on individuals and family life in Macao.

Secondly, many of the themes that emerged from the analysis of the textual data could be considered as universal problems also evident in other countries dominated by entirely different industries. We also do not negate the fact that some social and family issues could have existed in Macao for a long time and could possibly not be attributed, either in the past or now, to the gaming industry per se. Whereas the enabling and disabling processes regarding family life had been noticeable for a long time, most likely since the start of the Portuguese administration of the territory and, related to various industries, the rapid growth of the gaming industry in recent years has exacerbated these issues to some extent. Our focal point was nonetheless on describing, from a psychological perspective the perceptions and viewpoints of leaders in the community regarding the present ways in which the gaming industry affected family life and the psychological well-being of the people of Macao. There is for example a tendency amongst young people to forfeit furthering their education, both school and tertiary education, because of lucrative job opportunities in casinos, while parents who work in the industry typically have ongoing changing work shift schedules that easily disrupt their family life.

DiscussionPerceptions regarding the impact of the gaming industry on family functioning

Overall, a traditional "Macao approach" to life that valued a stable, easy-going lifestyle and taking things as they were without exerting much effort towards change were 
observed. As one interviewee indicated, "I heard my colleague say that Macao people can very easily be satisfied with what they have, but I feel that the newer generation has their ambition and that ambition may be to get "quick" money" $[01 / 01]^{30}$. Such an aim for harmonious living cannot be faulted in itself and it combines well with the traditional Chinese values of collectivism and moral qualities of loyalty and faithfulness. Past generations have emphasised ren ( $\mathrm{W}$, humanness) and yi (W, righteousness), good education and respect for life as central to the moral education of the young. Through engagement with the gaming industry, however, the younger generation have been encouraged to become involved in hedonistic behaviour patterns and a drive towards individualist needs and materialism. It seems that the harmonious co-existence of the past has mutated into a dependency on external forces and a need for wealth that has overshadowed good education and respect for life and impacted on the psycho-social well-being of the local population ("Local people become dependent on income from tourism and gambling and do not develop other industries. The gaming industry provides easy money; there is no motivation to work for their own well-being -enhance their competences and motivation to look beyond "soft money" that comes easily" [05/09]).

21 The rapid growth in the economy over the past five years and the increase in casino licences have resulted in a distinct escalation in employment opportunities mostly in the gaming industry, tourism industry and construction. Many people were able to find jobs in Macao either as croupiers in the casinos or in subsidiary sectors of the industry including professional services (e.g., bookkeeping), retail and services (e.g., cleaning, catering), and construction. As our interviewees pointed out, "the economy was rather slow in Macao but now it has increased...[and] with the opening up of China, we now get tours coming into Macao, making Macao very strong in its economy...increase in people's daily living standards" [01/01] and "the casinos also have a positive face where it provides a good income for the locals now" [02/07]. Recent figures showed that almost $58 \%$ of the local population worked in the gaming industry and that there will be an increase in the coming years when more casinos open in the territory. The increase in revenue gained from gambling taxes has made it possible for the Legislator to continue granting more subsidies to social services and families in general benefiting from the boom in the gaming industry. Recently it was also announced that education for all children would be free of charge up to completion of secondary school ${ }^{31}$.

The availability of work opportunities has in particular boosted migration of people from the mainland to Macao, and legal immigrants job seekers from mainland China between the ages of 20 and 60 was up from 1,583 in 2002 to 4,387 by the end of $2004^{32}$. Legal immigrants and people authorised to permanently reside in Macao contributed to a rise of $7.27 \%$ during the same period from 2002 to the end of $2004^{33}$. A concern was, however, uttered by the interviewees in our project. The availability of work opportunities in Macao, either in the casinos or elsewhere, often implied separation from family members when one partner moved to the SAR while the rest of the family still resided on the mainland. "There are some cases where the husband tries to ask the government to have his wife sent down to Macao from the mainland, but because they cannot wait for the long period of time, so by the time the wife gets here, the husband will already have a new wife" [01/02].

Although separation from the family cannot be attributed only to the gaming industry, the developments and available job opportunities in subsidiary industries such as 
construction due to the need for more hotels and renovations could be interpreted as an indirect role that the industry played in disrupting the family life of those who migrated to the territory. When the family then reunited after a period of separation, relationship problems often ensued that made living together again stressful. The influx of employable workers and preference given to young adults to work in casinos, for example, have also resulted in a change in the retirement age, putting middle-aged adults in danger of struggling to find suitable employment in order to provide for their families (01/03).

With regard to the family as functional unit, the working hours of employees in the gaming industry was pointed out by the interviewees in our project as a major concern. Casinos in Macao operate 24 hours a day so working in a casino often means "irregular time shifts of casinos, dividing working shifts into early and night shifts. When people have to go to work they will have to leave their children at home. This is a problem which leads to psychological problems" [01/03]. A key informant from the social service providers indicated that this was "especially the case when both parents work in the casino, and the children does not get a chance to be with them, and therefore they are bringing up themselves on their own" [01/01].

Two issues are relevant in this regard. Although not unique to the gaming industry (e.g., nurses, paramedics, and other service providers also work night shifts), the impact of irregular working hours and night shifts on the one hand influenced role appropriation and on the other jeopardised family relationships. In a society where traditional male and female roles were still dominant and gender stereotypes of the father as breadwinner and disciplinarian and the mother as taking care of nurturing needs still strictly adhered to, the ongoing changing work shift schedules could easily disrupt family life ${ }^{34}$. Role reversal challenged personal and cultural beliefs, while the absence of a role in the family (e.g., father/mother working night shifts, female single parent family) could exacerbate risk behaviours ("parents who have no control or poor discipline, mostly low education and unnatural working hours (working in factories, casinos, elsewhere), were the major problems encountered in Macao" [08/14]). From a psychological point of view, having and spending time with one another is one of the basic premises for establishing attachment relationships between family members and for parents to engage in the moral and cultural education of their children.

Perceptions regarding the impact of the gaming industry on family relationships

Problematic family relationships and emotional problems were among the prominent issues that social workers attended to during the first six months of 2005 with about $38 \%$ of cases that dealt specifically with one or more disrupted family relationships. The figures are not clear as to the number of cases directly related to the gaming industry, but it is not unlikely given that the industry plays such a major role in the material and psycho-social functioning of Macao families. During our fieldwork it was mentioned that, particularly with regard to families where one or both parents worked in casinos, "a lot of their relationships are all messed up and they cannot resolve this situation. The children of these people will be greatly affected [and] now there are also families who lock their elderly up at home" [01/02]. Although the exact reasons for locking up an elderly parent were not mentioned, it was disconcerting to know that the extended family was indirectly affected by disruptions in the family and probably by involvement in gambling related activities. However, this needs further exploration in the follow-up to this report. 
Without sufficient time and continuous interaction to respond to one another's needs family relationships were particularly at risk ${ }^{35}$. The perceived absence of parents as primary educators and socialisation agents of children, living in a society dominated by gambling and often experiencing the over-crowdedness that accompanies an influx of tourists to the territory, contributed much to the disrupting of family relationships and the psycho-social development of individuals. Whereas people appreciated the economic gains from the industry, families tended to avoid social areas where they could spend time together and interact with peers and friends because these places were also frequented by the tourists with whom they did not want to connect on a social level. As the director of one of the major social service providers in Macao indicated, "local people accept that tourism is good for the economy and open their minds to other lifestyles, but the education level of tourists is low resulting in an aversion by the local population to the influx of these people to the territory" [05/09].

Other relationship problems that were mentioned during our fieldwork included family violence ("domestic violence affects the woman's core self-esteem" [02/05]) and marital conflict ("a lot of extra marital relationships can lead to violence ...and affairs are also the cause of many family break-ups, having great effect on the children" [01/02]). Although family violence and abuse against women could not per se be attributed to the gaming industry (other factors most definitely also played a role). There was the suggestion by several interviewees that the emotional and relationship problems usually ensued from one or more members working in the gaming and subsidiary industries. Family members participating, for example, in the sex industry for additional income contributed its own set of problems in relationships and one interviewee commented that she has "found a lot of females-not the males-who are actually the causes of family problems ...having an affair ...especially in the central areas" [01/03]. Most distressing to most of our interviewees was, however, the prospective impact of disrupted family life, whether directly or indirectly related to the gaming industry or not, on parent-child relationships and child care.

Perceptions regarding the impact of the gaming industry on child care in the family

Parents, particularly those working in the gaming and related industries, often allowed children to go unsupervised or engaged social services to care for their children, displacing the responsibility of child care and parental education to sources outside the family. An informant working specifically with children in a very poor area in the north of Macao indicated that they were often confronted with cases "where both the kid's parents have to work the night-shift" and recalled a case where the parents "have asked if the centre could look after their child for them...we would need to set up a shelter for these people... their income does not permit them to employ someone to look after the child. In most cases $60 \%$ of them come from single parent families" [06/10]. Some parents engaged the extended family in child care ("grandparents take care of the child but they have no real power to discipline the child" [08/13]), whereas others sent their children to the mainland to stay with the family there for extended periods of time, almost losing contact with the child entirely.

Lack of parental guidance or a sound parent-child relationship has been indicated to be a major cause of problematic child behaviours. Psycho-emotional disturbances among children often emerged from feelings of rejection, neglect and lead to a lack of selfesteem and a decline in children's academic performance ${ }^{36}$. In Macao the situation was exacerbated by early exposure to gambling-related and subsidiary activities such as 
prostitution. Our respondent working mainly with single-parent families in the north of Macao, when talking about the influence of the gaming industry on children, indicated that toys such as miniature slot machines and playing cards were easily accessible and had as their aim "for these children to become addicted to them. For example, there are also toy cards that they can trade for money. These toy cards have also created problems where children have caused fights because they try to steal these valuable cards" [06/10]. One direct and very worrying consequence of the gaming industry is juvenile delinquency that has been gradually increasing as Lo Shiu Hing pointed out in his article on gambling and organised crime ${ }^{37}$.

31 A Macao-based gangster, cited by Lo Shiu Hing, "estimated that up to $80 \%$ of the youth in Macao have contract or connections with triads because they are forced to accept triad protection". For Lo, that was due to the rapid increase in Macao's population since newly arrived parents had to concentrate their time and energy in providing for their families and therefore neglected the children ${ }^{38}$. In the first nine months of 2005, 114 criminal cases involving 218 adolescents were handled in $\mathrm{Macao}^{39}$ and the Statistics and Census Services estimated that there was a $7.6 \%$ increase to $25.3 \%$ compared to the previous year ${ }^{40}$. In a blueprint study by the Social Welfare Institute, it was also indicated that $30 \%$ of adolescents in Macao have at one time or another been engaged in stealing, fighting or damaging public property ${ }^{41}$. During our fieldwork, we were told by a school director that he had to deal with a triad issue within the very premises of the school just prior to his interview with us. Minors were also frequent among court cases handled by the legal system, and "adolescents and children are seen in court because of shoplifting, stealing (forced entry in residential areas), fighting in public places... family background and friends are the cause for many problems among adolescents" (08/13).

32 Anti-social and gang-related behaviours are not uncommon among adolescents who are in the process of identity formation, particularly when they have to deal with problematic parent-child relationships, do not receive adequate moral education from their parents ("the school has to take over basic education from the family-the school becomes a substitute for the family" [03/07]), and are faced with negative labelling in society ${ }^{42}$. Although delinquent and gang behaviour of adolescents could again not be seen as a mere direct consequence of the boom in the gaming industry and parent absence because of employment in the industry, it seemed that young people were more at risk for engaging in unacceptable behaviours and that the gaming industry has to an extent aggravated the situation in recent years.

Perceptions of the impact of the gaming industry on psycho-social issues in the family

The groups mostly targeted for jobs in the gaming industry were the adolescents and young adults, people who have reached the age of 18 years and who could legally engage in economic activity. As one interviewee mentioned, "casinos have been able to attract a lot of teenagers to work for them" [01/02]. However, many of these young people forfeited further education and were attracted by lucrative salaries "taken out of school to go work in casinos where they can earn up to 10,000 patacas per monthsometimes higher than a graduate can earn" [08/13]. Estimates of exactly how many young people rejected further education in favour of so-called "easy money" and financial independence that flowed from working in the gaming industry were not available and we considered this as particularly an area for further investigation. Whereas the employment opportunities the industry offers were enabling in a major 
sense and young people could, as required by the tradition of filial piety, now better take care of their parents, disabling processes were also at work.

The easily accessible and lucrative employment available in casinos and the lack of motivation to pursue educational goals put young people at risk. They emphasise an immediate and short-term success and offer a gratification that together impede on a sense of directedness and purpose in life and the overall psychological well-being of people in Macao. Vocational interest is a product of positive family relationships, but the environment also plays a role in guiding young people towards a positive life orientation ${ }^{43}$. One of our key informants in particular pointed out that "lack of motivation for school achievement leads to drop-outs" [03/07], and it seemed that the wealth and prosperity brought about by the "lure factor of 'easy money' and recruiting children away from the education system" [03/07] affected family life in particular and had a "great impact on people's way of thinking and their mental development" [01/02].

35 Furthermore, the prospects of employment in the industry did not bring wealth and prosperity to all the people of Macao. Many local families, who had been in Macao for several generations, were suffering from an increase in poverty with real estate prices escalating rapidly, and the high price of consumables. It seemed that there were increasing numbers of families that could not maintain a good standard of living. This trend was emphasised by the Social Welfare Department reporting that 7,732 families applied for and received financial aid in the first half of 2005. Physical needs are among the most basic needs for psychological well-being because without sufficient gratification of physical and security needs, the individual could have difficulty focusing his or her psychological energy on belongingness and realisation of potentialities ${ }^{44}$. It seemed therefore that the gaming and related industries have their advantages and drawbacks. Macao families benefit perhaps from the job opportunities and increased salaries the industry offers, but at the same time they experience problematic family relationships and their overall psychological well-being is thus put at stake. Those who are not working for the gaming and related industries experience financial hardship due to the increase of the cost of living since the boom three years ago, and this new lacking of resources brings upon them new psychological stresses.

The gaming industry does indeed have an impact on family life. On the one hand, the industry has boosted economic growth in the enclave and material prosperity for the local residents. On the other, however, it also engenders several disabling and disruptive processes that have particularly affected the psychological well-being of individuals and families in Macao.

Reflecting on Macao within the perspective of the broader China, it was also odd to see how the "one-country-two systems" model worked in this specific case. Macao had been developing the gaming industry with the blessing not only of the SAR government but also of the highest authorities in Beijing, while those very same authorities have been campaigning since 2004 to crack down on gambling ${ }^{45}$. In January 2005, President $\mathrm{Hu}$ Jintao reiterated the need for China's youth to be equally ideologically and ethically educated ${ }^{46}$. Well, it seemed that under the "one-country-two systems" the youth of Macao did not enjoy the same treatment as the youth in the mainland ${ }^{47}$.

38 Maybe the most significant gap in our search for understanding was the lack of meaningful baseline research and in particular the lack of public data pertaining to, for example, shift work, the average age of employees in casinos, relations between wages 
and age, and information about subsidiary trades such as prostitution, drug peddling and triads. We had to rely on the perceptions of our key informants and a few public data bases (e.g., DSEC). Therefore, this initial exploration could by no means be considered comprehensive or adequately revealing of the extent and complexity of factors influencing the psychological well-being of the local community in Macao.

Psychological interventions and mental health care are not common practices in Chinese communities, and much still needs to be done to develop an understanding and appreciation among the people of Macao for such services. The next step of this research project will be to investigate the perceptions and attitudes of the local residents at grassroots level, the people actually working in the gaming and related industries, and identify their particular needs where psychological services are concerned. It would be helpful to include other participants from the various sectors, also the government and the gaming industry, in further investigations into the way in which psychology can be implemented in this society to enhance the psychological well-being of the people. We hope to explore, for example, the identity changes that have occurred among individuals and the community as a whole since the recent boom in the gaming industry and the handover of Macao to the PRC. Furthermore, we hope to develop, through ongoing research and activity, the necessary frameworks for providing psychological interventions that could empower the people of Macao and provide them with coping strategies to deal with the influences of the gaming industry on their individual and collective lives. Comparative studies and looking at other developing countries dominated by a single industry would also be relevant. The government has lately put some projects in place to encourage the implementation of psychological services, but further research will provide insights into establishing the necessary frameworks and infrastructure that can address the felt and anticipated needs in the community for such services.

\section{NOTES}

1. This article is the outcome of research undertaken with a grant from the University of Macau. The authors are all connected to the Faculty of Social Sciences and Humanities where they teach, respectively, psychology and sociology. Correspondence can be directed to the principle investigator at: gjvs@umac.mo.

2. We wish to thank all our key informants working respectively at Caritas, psychiatric nursing recovery services, elderly care centres, and youth centres for at-risk children and support of single parents, as well as the Ricci College (a secondary school in Macao) and leaders in schools and institutions for higher learning for their willing participation in this first part of the project. We also wish to thank the Macao Ricci Institute for having organised a seminar that was well attended by members of the Macao public and press for the first presentation of the outcomes of this project. To the public attending the MRI Forum on December 13th 2005 and to the reviewers of China Perspectives we extend a special word of appreciation for their comments that helped us improve this final version of the paper. 
3. Personal communication with Dr K K Tong, a collaborating researcher, September 2005.

4.Website of Direcção dos Serviços de Estatística e Censos (DSEC, Statistics and Census Service), http://www.dsec.gov.mo/e_index.html, last visited on December 12th 2005. 5. Monica McGoldrick, Randy Gerson and Sylvia Shellenberger, Genograms: Assessment and Intervention, New York, W.W. Norton \& Company, 1999, p. 7; see also Murray Bowen, Family Therapy in Clinical Practice, New York, Jason Aronson, 1978; Irene Goldenberg and Herbert Goldenberg, Family Therapy: an Overview, Australia, Brooks/Cole Thomson Learning, 2000; Christie Connard, "The Ecology of the Family. A Background Paper for a Family-Centered Approach to Education and Social Service Delivery" on http:// www.nwrel.org; Gertina van Schalkwyk, "Mapping family systems for ethical decision making" in Iva Smit, Wendell Wallach and George E. Lasker (eds.), Cognitive, Emotive and Ethical Aspects of Decision Making in Humans and Artificial Intelligence, Vol. IV, Canada, The International Institute for Advanced Studies in Systems Research and Cybernetics, 2005.

6. Goldenberg \& Goldenberg, op. cit. p. 19.

7. Website of Direcção dos Serviços de Estatística e Censos (Statistics and Census Service), http://www.dsec.gov.mo/e_index.html, last visit on December 12, 2005 8. Luo Lu, Robin Gilmour and Shu-Fang Kao, "Cultural values and happiness: An EastWest dialogue", in The Journal of Social Psychology, Vol. 141 No. 4, 2001, pp. 477-493. 9. Psychofortology as a domain is a contradistinction to psychopathology and studies the origins, nature, manifestations and enhancement of psychological well-being in the lives of individuals and communities. See e.g., Mustafah Ahmed Arafa, Mervat W.A. Nazel, Nahla K. Ibrahim and Ashraf Attia, "Predictors of psychological well-being of nurses in Alexandria, Egypt" in International Journal of Nursing Practice, Vol. 9, 2003, pp. 313-320; Paula Brough, "A comparative investigation of the predictors of work-related psychological well-being within police, fire and ambulance workers", in New Zealand Journal of Psychology, Vol. 34, No. 2, 2005, pp. 127-134; and Marie Wissing and Chris van Eeden, "Empirical clarification of the nature of psychological well-being", in South African Journal of Psychology, Vol. 32, No. 1, 2002, pp. 32-44.

10. See Irvin Yalom in Sheryl Zika and Kerry Chamberlain, "On the relation between meaning in life and psychological well-being", in the British Journal of Psychology, Vol. 83, 1992, pp. 133-145.

11. See Carol Ryff, "Happiness is everything, or is it? Explorations on the meaning of psychological well-being" in the Journal of Personality and Social Psychology, Vol. 57, 1989, pp. 564-577; and Carol Ryff and Corey L.M. Keyes, "The structure of psychological wellbeing revisited", in the Journal of Personality and Social Psychology, Vol. 69, 1995, pp. 719-727.

12. See e.g., Karen Duffy and Frank Wong, Community Psychology, New York, Allyn and Bacon, 2003 for more about developing service frameworks and the importance of primary prevention for empowering communities to cope with the impact of external challenges.

13. See, for example, James Dalton, Maurice Elias and Abraham Wandersman, Community Psychology: Linking Individuals and Communities, Canada, Wadsworth Thomson Learning, 2001.

14. Rolf D. Cremer (ed.), Macau: City of Commerce and Culture, Hong Kong, API Press, 1991. 15. Cited in Eric Sautedé, "The East Did Meet the West in Macao," HongKong-Echos, No. 37, Autumn 2005, pp. 14-16. 
16. Christina Miu Bing Cheng, Macau: A Cultural Janus, Hong Kong, Hong Kong University Press, 1999.

17. UNESCO added "The Historic Centre of Macao", covering some 20 historical landmarks, including the old façade of Saint Paul and the temple of A-Ma, on July 15th 2005 to its prestigious World Heritage List.

18. Fernando Figueiredo, “A Conjectura Política: Depois De Hong Kong”, in A. H. de Oliveira Marques, História Dos Portugueses No Extremo Oriente, op. cit. pp. 35-92.

19. Manuel Teixeira, o Comércio de Escravos em Macao / The So-Called Portuguese Slave Trade in Macao, Macao, Imprensa Nacional, 1976; and Fernando Figueiredo, op. cit., pp. 56-58.

20. As shown by Joãn de Pina-Cabral, especially Chapter 4: "Paradoxes: Gambling and the Imperial Civil Service Examination", Between China and Europe: Person, Culture and Emotion in Macao, London \& New York, Continuum, 2002. This chapter is one of the most, if not the most, comprehensive historical analysis of the gambling background of Macao. Indeed, as pointed out by the author himself, p. 81: "The history of these activities has not been researched in any systematic way. Most of the governmental archival material previous to 1960 relating to gambling contracts seems to have mysteriously vanished". There are some collections of materials mentioned by PinaCabral, like the green book of the Inspecção dos Contratos de Jogos published in 1985, and Ana Maria Amaro, Jogos, Brinquedos e Outras Diversões Populares de Macau, Macao, Imprensa Nacional, 1992. See also: Antonio Pinho, "Gambling in Macau”, in Rolf D. Cremer (ed.), op. cit., pp. 247-257.

21. Pina-Cabral, op. cit. p. 81.

22. Jacques Gernet, Daily Life in China on the Eve of the Mongol Invasion 1250-1276, London, George Allen \& Unwin Ltd, 1962.

23.Website of Direcção dos Serviços de Estatística e Censos (Statistics and Census Service), http://www.dsec.gov.mo/e_index.html.

24. Ibid.

25. Citing the President and Chief Operating Officer of the Las Vegas Sands (LVS) interviewed by Paulo Azevedo and José Ho in "We Became More Bullish About the Investment", Macau Business, December 2005, pp. 10-15.

26. Duffy \& Wong, op. cit.; Fred M. Cox, John L. Erlich, Jack Rothman and John E. Tropman (eds.), Tactics and Techniques of Community Practice, Itasca, Illinois, FE Peacock Publishers, 1984. Norman Denzin and Yvonna Lincoln also wrote on different methods used in qualitative research in their Handbook of Qualitative Research, London, Sage, 1999. 27. Steiner Kvale, Interviews: An introduction to qualitative research interviewing. London, Sage Publications, 1996.

28. We wish to thank our research assistant, Ms Jennifer Wilkinson, for the hours she spent transcribing and translating the audio recordings of the interviews we conducted for this project.

29. McGoldrick, Gerson \& Shellenberger, op. cit.

30. Throughout the discussion section we will refer to the comments and contributions of key informants who participated in this first part of the study in italics. We do not use the informants' names so as to protect their identity and a special code will indicated that the comments were made by different participants in this exploratory study.

31. Macau Post Daily, November 21, 2005.

32. DSEC, 2005. 
33. Macau Post Daily, November 21, 2005.

34. See Sing Lau (ed.) in Growing up the Chinese Way: Chinese Child and Adolescent Development, Hong Kong: The Chinese University Press, 1996.

35. Connard, op cit., and Goldenberg and Goldenberg, op cit., expand on the importance of time and space for forming quality relationships in the family.

36. See Harry Gardiner and Carol Kosmitzki, "Lives across cultures: cross-cultural human development", Singapore, Pearson Education, 2005, and Barbara and Philip Newman, "Development through life: a psychosocial approach", Singapore, Thomson Wadsworth Publishers, 2003.

37. Lo Shiu Hing, "Towards the End of the Stanley Ho Connection?" China Perspectives, "Macau Special", op. cit. pp. 56-65.

38. Ibid., p. 59.

39. As reported in Macau Daily, http://www.macau.ctm.net/modailylog/20051110/ index.htm.

40. DSEC, 2005.

41. Youth Problems and Youth Services in Macau SAR: A blueprint for the new millennium, published by the Social Welfare Institute, 2005, and Wu Zhiliang, A juventude e o futuro de Macau, Qingnian yu Aomen weilai, The Youth and the Future of Macau, Fundação Macau, 1994.

42. Gardiner and Kosmitzki, op. cit.; Barbara and Philip Newman, op. cit. 43. See Ryff, op. cit.; Lea Pulkkinen and Anna Ronka, "Personal control over development, identity formation, and future orientation", in Developmental Psychology, Vol. 30, 1994, pp. 260-271; and Oi-Ling Siu, "Occupational stressors and well-being among Chinese Employees" in Applied Psychology, Vol. 51(4), 2002, pp. 527-544 44. See for example, Maslow's hierarchy of needs and the potential impact of unsatisfied deficiency needs in George Boeree's summary of Abraham Maslow, http:// www.ship.edu/ cgboree/maslow.html.

45. "China launches nationwide campaign against gambling”, People's Daily Online, last updated on January $12^{\text {th }} 2005$, http://english.people.com.cn/200501/12/ eng20050112_170335.html.

46. "Chinese president urges ethical, ideological education for youth," People's Daily Online, last updated on January $19^{\text {th }} 2005$, http://english.people.com.cn/200501/18/ eng20050118_171045.html.

47. For further development on politics and ethics, see Emilie Tran, "Elite Politics and Ethics in China: Resolving Non-Antagonistic Contradictions?", Chinese Cross Currents, "Success and Values", Vol. 2, No. 2, April-June 2005, pp. 50-69.

\section{RÉSUMÉS}

The purpose of this article is to present a comprehensive situation analysis and an assessment of the needs of the people of Macao in terms of their psychological well-being. It describes the present situation with regard to the ways in which the gaming industry affects family life and challenges the psychological well-being of the residents of Macao. Action research and a key 
informant approach were the basic methodology for this study, and semi-structured interviews were conducted to gain an understanding of the enabling and disabling processes in family life through the impact of the gaming industry. Textual data were analysed qualitatively for four dimensions. Four themes emerged-family functioning, relationships, child care and psychosocial issues in the family. Although not the only influence, it seems the gaming industry does indeed affect the family unit and the psychological well-being of individuals and groups both directly and indirectly ${ }^{1}$. 